\title{
Evaluation of Caregiver's Transfer Heights by Analyzing Muscle Activity on a Shower-Carrier System
}

\author{
Jong Hyun $\mathrm{Kim}^{1}$, Byeong Hee Won ${ }^{1}$, Jae Soo Hong ${ }^{1}$ \\ ${ }^{1}$ Biomedical System \& Technology Group, KITECH, Cheonan, Korea \\ jshong94@kitech.re.kr
}

\begin{abstract}
Korean population is ageing rapidly; as a result, the number of elderly individuals living in hospitals and nursing homes has increased. As such, caregivers in the hospital and nursing home settings are exposed to musculoskeletal disorders that accompany aging and must help the patients change positions. Skillful transfers are among the most difficult nursing tasks. Therefore, this study aimed to suggest a guideline for the height of a suitable transfer through a usability evaluation of the transfer height between a shower carrier and a bathtub.

In this study, height-adjustable experimental equipment for transferring a patient between a shower carrier and a bathtub was constructed. The muscle activity at heights of $65,70,75,80,85$, and $90 \mathrm{~cm}$ was measured using a wireless surface electromyography system. In this experiment, a commercially available mobile bed was used with the experimental equipment. Activity was measured in the following 4 muscles: upper trapezius, biceps, triceps, and erector spinae.

The results of this study showed the lowest muscle activity at the transfer height of $80 \mathrm{~cm}$. Trends in muscle activity changes based on an experiment focusing on caregivers suggested that the suitable transfer height for caregivers was 78$81 \mathrm{~cm}$. As such, the patient's perspective was not considered in this study. A future usability evaluation will focus on ideal transfer height from the patient's perspective.
\end{abstract}

Keywords: Multifunctional Mattress, Vibroacoustic Stimulation, Planar Heating, Local Climate Management, Usability Evaluation

\section{Introduction}

Due to a rapidly aging population in Korea, there has been an increase in the number of patients living in nursing homes and specialized senior hospitals [1]. Hospitals as well as nursing homes use various types of indoor mobility equipment. Typical indoor mobility aids (such as wheelchairs, shower lifts, and shower carriers) are designed to ease the physical burden on caregivers and to assure the safety of the elderly [2]. However, as mobility equipment has been developed, it has become necessary for caregivers to transfer the elderly between these various equipment or between the equipment and living spaces [3 5]. For the elderly using these equipment, transfer-related motions have become a part of their daily life $[6,7]$.

In Japan, U.S.A, and Europe etc., research is currently being conducted to study transfer-related motion patterns, and various new transfer aids are being developed to make the transferring convenient [8]. In addition, equipment that use a combination of docking systems for mobility and transfer have a convenient transfer system. An example of this type of product is the carrier system with a bathtub, which assures an easy transfer using a shared docking system between the bathtub and carrier $[9,10]$.

Although Japan's carrier system with a bathtub that used the railing and docking function improved the convenience of transfer, it was designed without prior experiments and research on the operating range, height of the handle, and the location of caregivers. Due to this, caregivers at nursing homes and specialized senior hospitals who are in charge of elderly patients' shower, bath, and treatment complain about pressure on their musculoskeletal systems and difficulties during the transfer [11 13]. Additionally, while the bathtub of the existing product has a lifting function, the unadjustable height of the docking system leads to the transfer being performed at a very low height [9].

In this study, we used electromyography (EMG) measurements [14] and motion capture to evaluate the height of the carrier system with a bathtub from the caregivers' perspective, in order to identify the optimum height for the transfer.

\section{Method}

Subjects: Five male subjects with a standard body [15] in their late twenties and early thirties participated in this study. The study was conducted after the entire experiment was explained to the subjects. The subjects had no history of upper limb surgeries and did not have any injuries or pain in either upper limb. The subjects had a mean age of $29.8( \pm 2.04)$ years, height of 176.8 $( \pm 3.11) \mathrm{cm}$, and weight of $79.6( \pm 3.11) \mathrm{kg}$.

Experiment Equipment: In order to evaluate the transfer height of the carrier system with a bathtub, a 6level height-adjustable experimental equipment for measuring the transfer height at $5 \mathrm{~cm}$ intervals from $65-$ $90 \mathrm{~cm}$, it was designed and produced. In this study, the main goal of the experimental equipment was to allow the transfer to take place at an exact height. The main parts of the equipment were: a shower bed to be transferred to, a docking rail system that aids the 


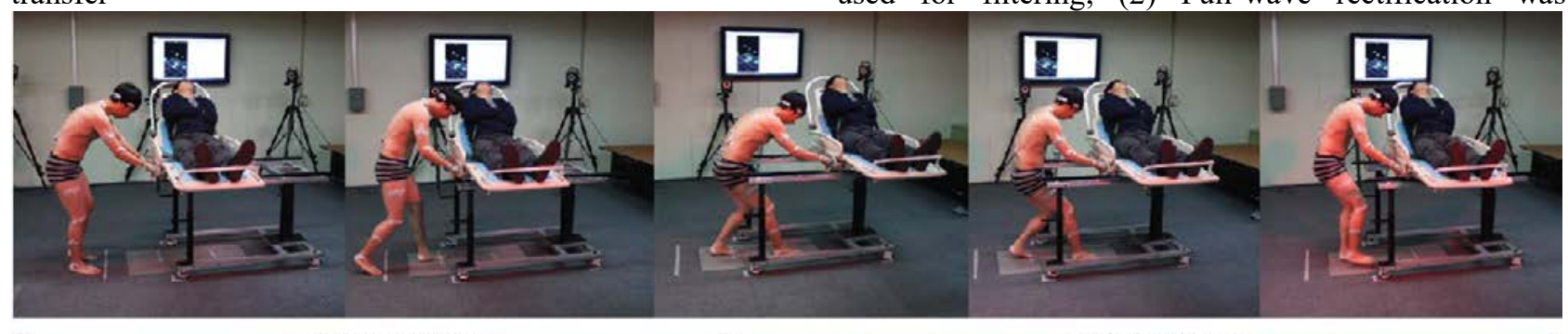

Pushing motion

Pulling motion

Figure 1. The scene of experiment: motion's procedure

to the bed, and height-adjustable equipment for controlling the transfer height. The existing shower bed (HK-231, OG-Giken Co. Ltd.) was used in the height adjustment experiment. Thus, the docking rail was designed in keeping with the design of the bed. The height-adjustable equipment was designed and produced manually using a latch.

Measurements and data acquisition: Ten MX-T20 cameras (Vicon Motion Systems INC., UK) were used to analyze the motion steps of the caregiver transfers and were synchronized with a Trigno Wireless EMG (16 channels, Delsys Inc., USA) EMG. An sEMG is widely used in many studies because it is completely noninvasive. The system used in the present study allowed 4 muscles (the upper trapezius, biceps, triceps, and erector spine) to be measured using 8 channels. Round, disposable electrodes were used as preamplified EMG wireless leads (gain: 500, bandpass: 10-1000 Hz, Delsys Inc., USA). To decrease the electric impedance of the skin, the area where the electrode was to be attached was first cleaned with alcohol. Elastic bandages were used to support the electrodes, and the experiment was only performed when the impedance values were under $50 \mathrm{~mA}$.

For the 3D motion capture, a total of 35 markers were attached to the subjects using a plug in gait full body marker set.

The EMG measurements and 3D motion captures were repeated 3 times at each of the 6 heights. Each subject consistently performed 2 types of transfer-related motions: pushing and pulling. To minimize the error range of the experimental results due to gait differences, the average adult stride was marked on the floor to assist the subjects in taking the same number of steps (Figure 1).

Data analysis: The results of EMG measurement and synchronized 3D motion analysis served as data to distinguish pushing and pulling motions during the transfer. Motion capture data was post-processed using Vicon Nexus 1.8 (Vicon Motion Systems INC., UK).

From Vicon Nexus1.8, 3D motion and synchronized EMG Data were printed out in the American Standard Code for Information Interchange (ASCII) form, and were analyzed using MyoResearch XP Master 1.06 (Noraxon System Inc., USA).

The post-processing of EMG data was performed as follows: (1) A bandpass (10-350 Hz) FIR filter was performed to obtain the average, maximum, and width values of the amplitude. Rectification was performed using an

electrical device by converting a negative amplitude to a positive one (the raw EMG before rectification is not so readily interpretable that its average value is zero). (3) Data was smoothed at a $30-\mathrm{ms}$ sampling rate, and the root mean square value was obtained. A 3-level postprocessing of EMG data was carried out as follows. During the post-processing of the EMG data, we omitted the normalization process that is usually carried out for overcoming the differences in each subject's muscle characteristics. This was because the goal of this study was not to compare the resultant values of muscle activities among the subjects, but rather to compare the resultant values of muscle activities at different transfer heights based on the muscle activities in the same subjects [16].

The resulting values of muscle activities at each transfer height were derived using the peak values of pushing and pulling motions.

\section{Results}

Upper trapezius (Figure 2): At every height, it was activated more intensely during pushing than pulling. The change in the peak value was the highest at $65 \mathrm{~cm}$ $(515 \mu \mathrm{V})$, and the lowest at $80 \mathrm{~cm}(229 \mu \mathrm{V})$.

Biceps (Figure 3): At $65 \mathrm{~cm}, 70 \mathrm{~cm}$, and $75 \mathrm{~cm}$, it was activated in both pushing and pulling motions, and at 80 $\mathrm{cm}, 85 \mathrm{~cm}$, and $90 \mathrm{~cm}$, the activation was more intense during pulling. Especially at $90 \mathrm{~cm}$, a major activation occurred during pulling. The change in the peak had the highest value of $812 \mu \mathrm{V}$ at $70 \mathrm{~cm}$, and the lowest value of $498 \mu \mathrm{V}$ at $80 \mathrm{~cm}$.

Triceps (Figure 4): At every height, it showed more activation during pushing motions. The change in the peak value reached the highest value of $397 \mu \mathrm{V}$ at 65 $\mathrm{cm}$, and the lowest value of $232 \mu \mathrm{V}$ at $80 \mathrm{~cm}$.

Erector spinae (Figure 5): No remarkable activation was observed in pushing or pulling motions, but more movements were noted while pulling. The peak values of each height were not significantly different. The peak value was the highest at $75 \mathrm{~cm}(292 \mu \mathrm{V})$, and the lowest at $90 \mathrm{~cm}(247 \mu \mathrm{V})$. 


\section{Discussion and Conclusion}

In the present study, a 3D motion capture camera and wireless surface EMG system were used to distinguish the pushing and pulling motions in 5 young men, and comparative analyses were performed on the activities of 4 upper body muscles at different transfer heights.

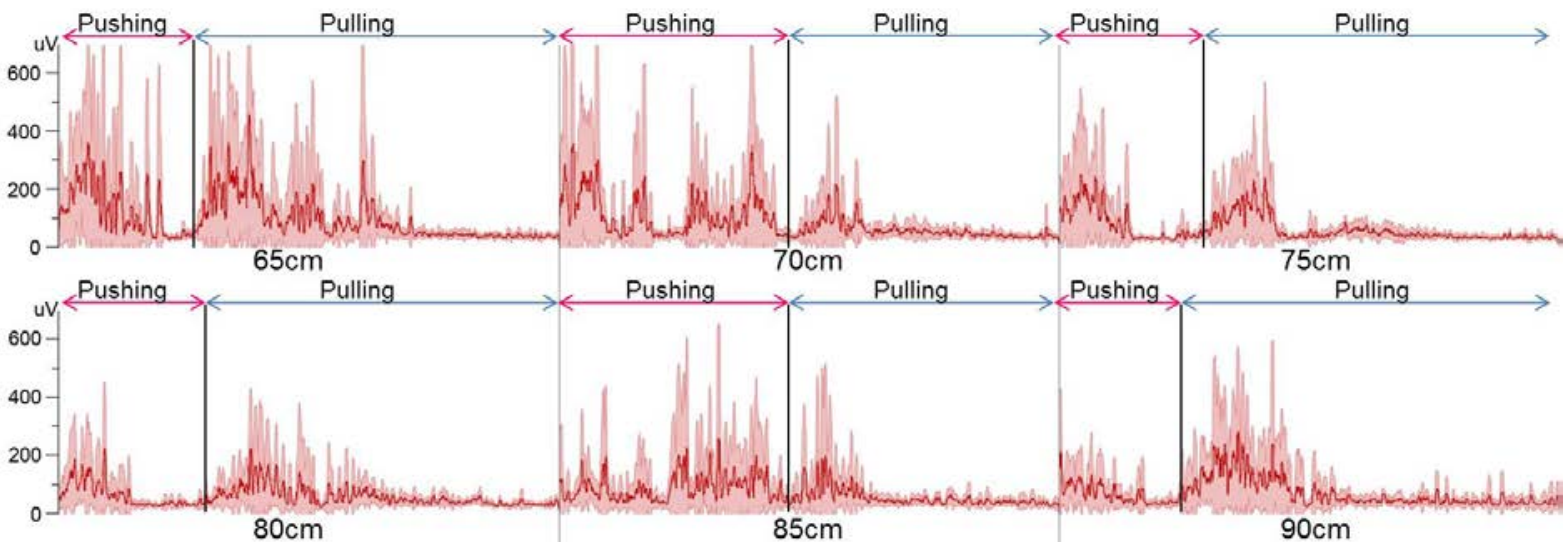

Figure 2. The result of upper trapezius activity by transfer's height

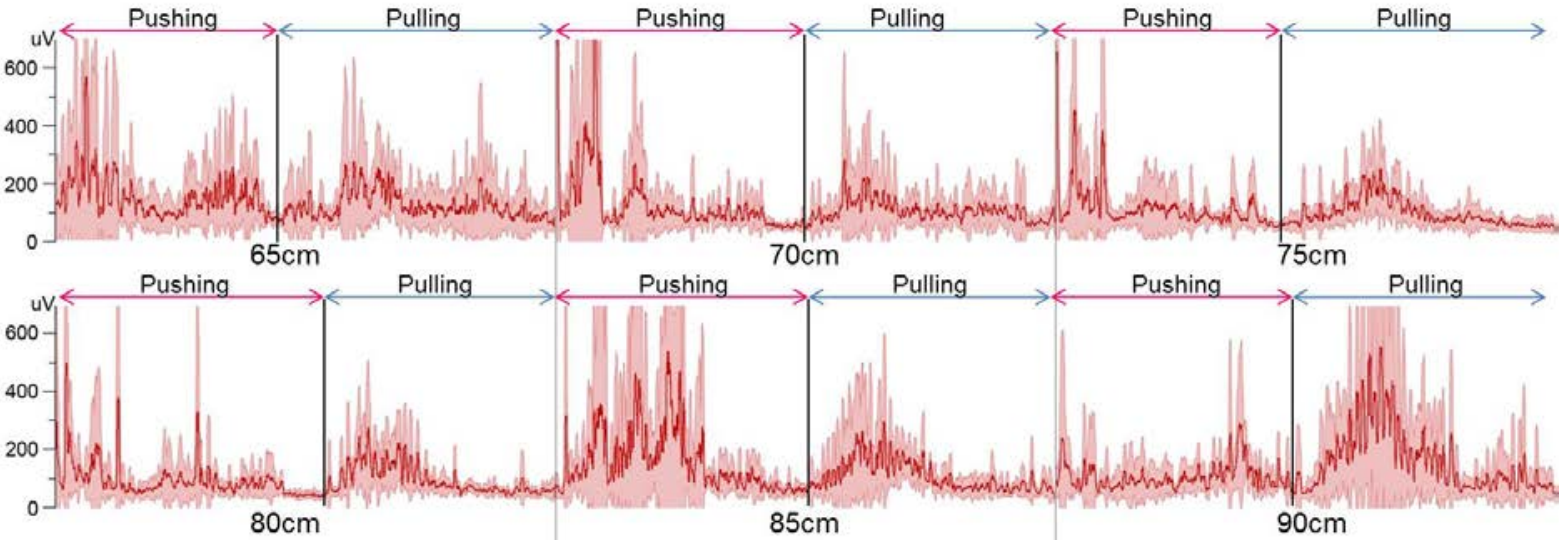

Figure 3. The result of biceps activity by transfer's height
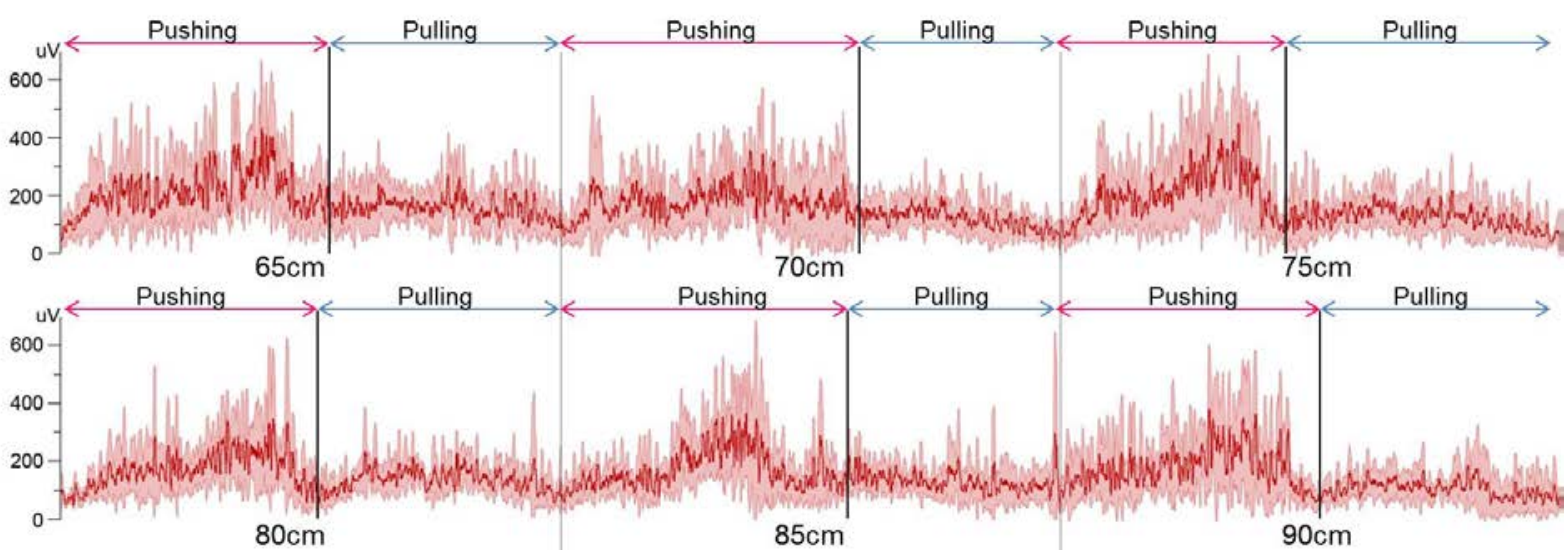

Figure 4. The result of triceps activity by transfer's height

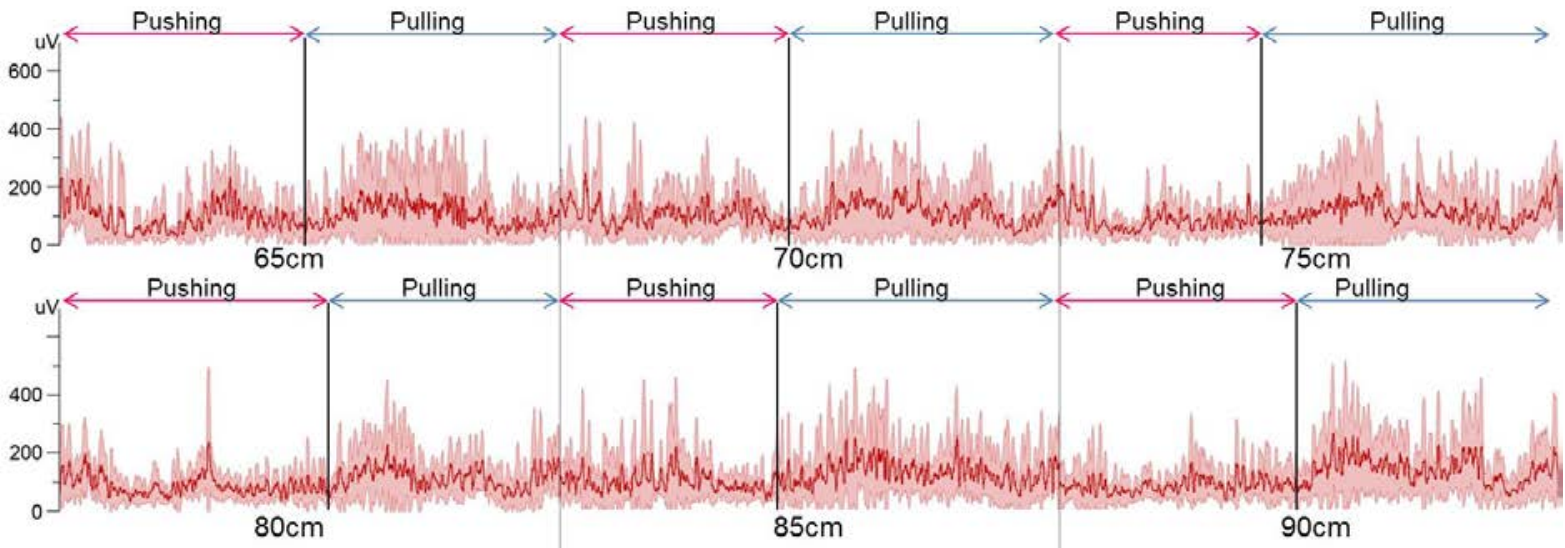

Figure 5. The result of erector spinae activity by transfer's height 
The experimental results revealed that the point where each muscle was activated was different, and with the exception of the biceps, they tended to be activated by a particular motion. During pushing motions at $90 \mathrm{~cm}$, the upper trapezius, triceps, and biceps were activated, and during pulling motions at $65 \mathrm{~cm}, 70 \mathrm{~cm}$, and $75 \mathrm{~cm}$, only the biceps were activated. The erector spinae muscles were activated during both pushing and pulling motions.

All muscles showed the lowest level of activation at 80 $\mathrm{cm}$. Therefore, based on the results of this study, the optimal transfer height of a carrier system with a bathtub was set between $78 \mathrm{~cm}$ and $81 \mathrm{~cm}$.

This optimization of height is based on previous study findings that explain intensity of muscle activation is indicative of the amount of the burden on the muscle, and that a frequent burden on muscle can induce musculoskeletal disorders.

Of course, when it comes to the transfer height, it would also be more efficient to use a height-adjustable carrier or a docking system that can be adjusted according to body sizes. Therefore, we expect that the results of this study will be useful as base data to optimize transfer height, even in adjustable equipments. We hope that the results of this study will also be useful to future studies investigating the reduction of the physical burden of caregivers working at large hospitals or nursing homes.

\section{ACKNOWLEDGEMENTS}

This research was supported by Korea Institute of Industrial Technology and Ministry of Health and Welfare, Republic of Korea.

\section{Contact}

More information is available at: Jae Soo Hong: jshong94@kitech.re.kr Jong Hyun Kim: ddalki@kitech.re.kr

Byeong Hee Won: bhwon@kitech.re.kr

\section{References}

[1] Chun, K. J., Kim, J. H., Hong, J. S., Development of an electric mobile and elevating chair for indoor, Report of Health \& Medical Technology R\&D Program, Ministry of Health \&Welfare, Seoul (2010).

[2] J. S. Kong, and B. H. Lee, Development of the Driving-will Control System for a Power-assisted Electric Wheelchair, Journal of the Korea AcademiaIndustrial, Vol. 13(2012), pp. 1296-1301.

[3] T. Dutta, P. J. Holliday, S. M. Gorski, M. S. Baharvandy, and G. R. Fernie, A biomechanical assessment of floor and overhead lifts using one or two caregivers for patient transfers, Applied Ergonomics, Vol. 43(2012), pp. 521-531.

[4] Julie J., Dianne M., Jessica C., and Daniel J., Development and Psychometric Properties of the SelfEfficacy Scale for Transfers for Caregivers of Children Requiring Transfer Assistance, Arch Phys Med Rehabil, Vol. 88(2007), pp. 481-488.
[5] R. L. Kirby, N. J. Mifflen, D. L. Thibault, C. Smith, K. L. Best, K. J. Thompson, and D. A. Macleod, The Manual Wheelchair-Handling Skills of Caregivers and the Effect of Training, Arch Phys Med Rehabil, Vol. 85(2004), pp. 2011-2019.

[6] Adelheid Z., Sabine H., Ian N., Gerjo K., Theo D., and Ruud J. G. H., Aggressive Behavior of Nursing Home Residents Toward Caregivers: A Systematic Literature Review, Geriatric Nursing, Vol. 3, No. 2(2009), pp. 174-186.

[7] Tilak D., Pamela J. H., Susan M. G., Mohammad S. B., and Geoff R. F., The effects of caregiver experience on low back loads during floor and overhead lift maneuvering activities, International Journal of Industrial Ergonomics, Vol. 41(2011), pp. 653-660.

[8] R. Hepherd, Technology applied to geriatric medicine Aids for bathing and showering, European Geriatric Medicine, Vol. 2(2011), pp. 190-193.

[9] OG-Giken, Nursing Care-Bath System, http://www.og-giken.co.jp/product/care.html, Japan, (2010).

[10] T. Yamazaki, The Ubiquitous Home, International Journal of Smart Home, Vol. 1(2007), pp. 17-22.

[11] Yeh, S. H., Johnson, M. A., and Wang, S. T., The changes in caregiver burden following nursing home placement, International Journal of Nursing Studies, Vol. 39(2002), pp. 591-690.

[12] J. Wiles, Daily geographies of caregivers: mobility, routine, scale, Social Science \& Medicine, Vol. 57(2003), pp. 1307-1325.

[13] W. S. C. Luk, The home care experience as perceived by the caregivers of Chinese dialysis patients, International Journal of Nursing Studies, Vol. 39(2002), pp. 269-277.

[14] H. J. Jang, J. S. Kim, J. D. Choi, and S. Y. Kim, The Effects of hand Grip Force on Shoulder Muscle Activity in Two Arm Posture, Journal of the Korea Academia-Industrial, Vol. 13(2012), pp. 1296-1301.

[15] Korean Agency for Technology, http://sizekorea.kats.go.kr, Korea (2010).

[16] J. S. Hong, J. H. Kim, J. H. Hong, and K. J. Chun, Electromyograph Analysis during Isokinetic Testing of Shoulder Joint in Elderly People, Journal of Biomechanical Science and Engineering, Vol. 7(2012), pp. 379-387. 